\title{
O processo educacional de estudante com deficiência visual: uma análise dos estudos de teses na temática
}

\author{
Marcia Rosa Uliana* \\ Gerson Souza Mól**
}

\section{Resumo}

O propósito do estudo relatado neste foi inventariar e discutir as teses que tiveram como objeto de estudo o processo educacional de estudante com deficiência visual no território brasileiro. Para tanto, foi realizada uma pesquisa de cunho bibliográfico, numa abordagem qualitativa, que teve como fonte de dados 50 resumos de teses, localizadas em bancos de teses disponíveis on-line, que abordavam questóes relacionadas ao processo educacional de estudante com deficiência visual. Neste artigo apresentamos e discutimos alguns aspectos gerais dessas teses: instituiçóes do curso de pós-graduação; nomes dos programas; abordagem da pesquisa; instrumentos de coletas de dados; objetivos das pesquisas; sujeitos envolvidos e áreas de conhecimento desses estudos. Contudo, nossos principais elementos de análise foram os focos temáticos de estudo dentro dos processos educacionais envolvendo estudante com deficiência visual e os resultados obtidos com tais pesquisas. Os aspectos investigados nos levaram a concluir que, apesar de os alunos com deficiência visual serem tão capazes como os demais, estes não estão vivenciando processos de inclusão eficientes, visto que lhes faltam livros didáticos em Braille, materiais didáticos adaptados, estruturas físicas adequadas às suas necessidades, professores que conheçam suas particularidades e planejem aulas utilizando recursos essenciais para a real inclusão. No entanto, apesar de algumas teses apresentarem açóes exitosas na formação de professores e que há profissionais aptos para promover a inclusão de estudantes deficientes visuais, uma boa parte delas alerta para o fato de que a maioria dos professores não se mostra preparada para a inclusão de alunos com deficiência visual nas escolas da Educação Básica.

Palavras-chave: Deficiência visual; Processo educacional; Inclusão.

\footnotetext{
* Professora doutora da Universidade Federal de Rondônia, Porto Velho, Rondônia, Brasil.
}

** Professor doutor da Universidade de Brasília, Brasília, Distrito Federal, Brasil. 


\section{The student educational process with visual disabilities: an analysis of theses studies on the topic}

\section{Abstract}

The purpose of the study reported in this was to inventory and discuss the theses that had as object of study the student educational process with visual disabilities in Brazil. For this purpose, a bibliographical research was conducted in a qualitative approach that had as a data source 50 abstracts of theses, located in theses banks available online, which addressed issues related to student educational process visually impaired. In this article we present and discuss some general aspects of these theses: Courses institutions graduate; names of programs; approach to research; tools for data collection; objectives of the research; subjects involved; and knowledge areas of these studies. However, our main elements of analysis were the thematic focus of study within the educational processes involving student with visual impairment and the results of such research. The investigated aspects led us to conclude that although students with visual disabilities to be as capable as others are not experiencing efficient inclusion processes, as they lack textbooks in braille, adapted learning materials, adequate physical structures to their needs, teachers who know their particularities, and plan classes using essential resources for real inclusion. However, despite some theses present successful actions in the training of teachers able to favor the inclusion of visually impaired students, a good portion of them alert to the fact that most teachers show up unprepared for the inclusion of students with visual impairment in Basic Education schools.

Keywords: Visual impairment; Educational process; Inclusion.

\section{Introdução}

Visando compreender como vem ocorrendo o processo educacional de pessoas com deficiência visual no ensino formal brasileiro, quais são suas tendências e perspectivas, realizamos um inventário e uma análise descritivo-interpretativa das teses desenvolvidas sobre essa temática.

Apesar do grande número de monografias e dissertaçóes feitas nesse campo de pesquisa, restringimos nosso estudo às teses por apresentarem estudos mais densos e aprofundados. Esperamos, dessa forma, trabalhar com dados e análises mais contundentes, apresentando um quadro mais confiável de como vem acontecendo o processo educacional de estudantes com deficiência visual. Cabe esclarecer que se entende por deficiência visual toda perda ou alteração orgânica que comprometa a visão, considerando classificaçôes já estabelecidas sobre a intensidade dessa perda de acuidade visual. Conforme o Decreto de Lei $\mathrm{n}^{\circ}$ 5.296, de 2004, é considerado cego todo o indivíduo que possui acuidade visual igual ou inferior a 0,05 no melhor olho, com a melhor correção óptica. Indivíduo com baixa visão, o que possui acuidade visual entre 0,3 e 0,05 no melhor olho, com a melhor correção óptica ou quando a somatória da medida do campo visual de ambos os olhos for igual ou inferior a $60^{\circ}$ ou que acumule a ocorrência de quaisquer das condiçóes mencionadas. 
Apesar de sabermos que as teses não representam toda a produção na temática delimitada, as produções dos programas de Pós-graduação strito sensu emergem dos elos entre pesquisadores experientes e iniciantes, que atuam em diversas instituiçóes por todo o país. Com isso, investigam a temática em diferentes contextos e expressam uma diversidade de olhares (TEIXEIRA; MEGID NETO, 2002), constituindo, de certa forma, uma amostra representativa do que é pesquisado nessa temática e, consequentemente, esboçando um panorama do que tem sido feito nessa área no Brasil, como é objetivo desse trabalho.

\section{A inclusão de estudantes com deficiência visual}

No Brasil, o processo de inclusão de estudantes com deficiência no ensino regular ganhou maior dinamismo a partir da década de noventa do último século com o paradigma de Educação Inclusiva. Esse está alicerçado em uma série de leis e documentos, dentre os quais destacamos a Declaraçáo de Salamanca de 1994, e a terceira Lei de Diretrizes e Bases da Educação (LDB), Lei no 9.394/96. Essas leis apontam para a necessidade de que a educação de todos os estudantes, sem qualquer distinção, deve acontecer na escola comum. Essas leis, apoiadas por diversos documentos oficiais, estabelecem inúmeras diretrizes para atender as demandas particulares dos estudantes com necessidades educativas especiais no processo educacional. Tais como os especificados no artigo 59 da Lei $n^{\circ} 9.394 / 96$ :

I - currículos, métodos, técnicas, recursos educativos e organizaçáo específica, para atender às suas necessidades;

II - terminalidade específica para aqueles que não puderem atingir o nível exigido para a conclusão do Ensino Fundamental, em virtude de suas deficiências, e aceleração para concluir em menor tempo o programa escolar para os superdotados;

III - professores com especialização adequada em nível médio ou superior, para atendimento especializado, bem como professores do ensino regular capacitados para a integração desses educandos nas classes comuns;

IV - Educaçáo Especial para o trabalho, visando a sua efetiva integração na vida em sociedade, inclusive condiçóes adequadas para os que não revelarem capacidade de inserção no trabalho competitivo, mediante articulação com os órgãos oficiais afins, bem como para aqueles que apresentam uma habilidade superior nas áreas artística, intelectual ou psicomotora;

$\mathrm{V}$ - acesso igualitário aos benefícios dos programas sociais suplementares disponíveis para o respectivo nível do ensino regular. (BRASIL, 1996)

O expresso neste artigo de Lei são elementos contundentes para que o ensino inclusivo seja a prática da inclusáo de todos - independentemente de seu talento, deficiência, origem socioeconômica ou origem cultural - ocorra em escolas e salas de aulas provedoras, onde todas as necessidades dos estudantes sejam satisfeitas (STAINBACK; STAINBACK, 1999). Todavia, há no Brasil um distanciamento alargado entre o que está prescrito nas leis e documentos e o que de fato é efetivado no cotidiano dos estabelecimentos de ensino (MAZZOTTA, 2011). Essa afirmação se 
confirma quando analisamos pesquisas que investigam esse fenômeno como a de Costa (2012), Pansini e Matos (2014), Menezes (2008), Duek (2011), Camargo (2008) e Urzêda (2012) as quais denunciam que muitos estudantes com deficiência não estáo inclusos por falta de condiçóes adequadas para a efetivaçáo do processo educacional.

Diante do exposto, e com interesse de conhecer em específico sobre o processo educacional de estudantes com deficiência visual, desenvolvemos esse trabalho para inventariar e analisar os resultados das teses que tiveram como objeto de estudo o processo educacional de estudantes com deficiência visual no território brasileiro. Acreditávamos que assim obteríamos um panorama de como vem ocorrendo o processo educacional de estudantes com deficiência visual no país.

\section{Percurso metodológico}

Tendo em vista os objetivos norteadores do presente estudo, realizamos um mapeamento das teses que abordam o processo educacional de pessoa com deficiência visual, configurando assim uma pesquisa bibliográfica com foco na análise dos dados por meio de uma abordagem qualitativa.

Inicialmente, como fonte de coleta dos dados, escolhemos o Banco de teses da Capes que, tradicionalmente, integraliza as produçóes dos diferentes programas de Pós-Graduação strito sensu do Brasil. No entanto, após percebemos que as teses defendidas nos últimos anos não estavam disponibilizadas, ampliamos nossas buscas para os bancos de dados das principais universidades brasileiras, além do site da Biblioteca Digital Brasileira de Teses e Dissertaçóes (IBICT). Em decorrência desses fatores não podemos afirmar que as produçóes apresentadas na sequência é o todo das teses produzidas na temática, mas acreditamos que é um número significativo e que apresenta um panorama nacional do que tem sido feito nessa área no Brasil.

Foram utilizadas como descritores nas buscas as seguintes palavras/expressóes: deficiência visual, acuidade visual, cego e cegueira. Cabe destacar que, durante a coleta, descartamos as teses que náo tinham como objeto a questấo da deficiência visual articulada, direta ou indiretamente, ao âmbito educacional.

\section{Resultados e discussão}

Ao todo foram mapeados 50 estudos que resultaram em tese e abordam o processo educacional das pessoas com deficiência visual no Brasil. No entanto, o recorte temporal do mapeamento se definiu após o término da coleta do material, ficando entre 1990 e 2014, ano da defesa da tese mais antiga e das mais recentes. No Quadro 1 apresentamos a distribuição das teses mapeadas pelo ano de defesa.

Quadro 1 - Distribuição anual das teses

\begin{tabular}{|c|c|c|c|c|c|c|c|c|c|c|c|c|c|}
\hline $\mathbf{1 9 9 0}$ & $\mathbf{2 0 0 1}$ & $\mathbf{2 0 0 2}$ & $\mathbf{2 0 0 4}$ & $\mathbf{2 0 0 5}$ & $\mathbf{2 0 0 6}$ & $\mathbf{2 0 0 7}$ & $\mathbf{2 0 0 8}$ & $\mathbf{2 0 0 9}$ & $\mathbf{2 0 1 0}$ & $\mathbf{2 0 1 1}$ & $\mathbf{2 0 1 2}$ & $\mathbf{2 0 1 3}$ & $\mathbf{2 0 1 4}$ \\
\hline 1 & 4 & 1 & 6 & 3 & 3 & 3 & 5 & 5 & 5 & 5 & 5 & 2 & 2 \\
\hline
\end{tabular}

Fonte: Elaborado pelos autores a partir dos dados coletados nos bancos de teses 
Como pode ser observar no Quadro 1, nos anos de 1991 a 2000 e em 2003 não encontramos nenhuma tese sobre a temática investigada. Os motivos podem ser a pouca ou ausência de produçáo na temática ou a dificuldade de concentrar/ disponibilizar os trabalhos nos bancos das instituiçốes na versão online. Isso porque na década se 1990 ainda era muito restrito o uso de computadores e não se tinha a preocupação de disponibilizar as produçóes em meio digital.

No que se refere às instituiçóes nas quais os trabalhos foram desenvolvidos, percebemos que há grande concentração em algumas poucas instituiçôes. Dos 50 trabalhos, $30(60 \%)$ estáo vinculadas a quatro instituiçôes, as 20 demais produçôes são oriundas de 14 instituiçóes diferentes. Conforme pode ser analisado nos dados apresentados no Quadro 2, as instituiçôes com maior número de produção foram a Universidade Federal de Sáo Paulo, a Universidade Estadual de Campinas, a Pontifícia Universidade Católica de São Paulo e a Universidade Federal do Rio Grande do Sul.

Quadro 2 - Distribuição das teses por Região, Estado e Instituição - (1990/2014)

\begin{tabular}{|c|c|c|c|}
\hline Regiáo & Estado & Instituição & $\begin{array}{c}\text { Número } \\
\text { de } \\
\text { Teses }\end{array}$ \\
\hline \multirow{9}{*}{$\begin{array}{l}\text { Sudeste } \\
(36 ; 72 \%)\end{array}$} & \multirow{6}{*}{ SP } & Universidade de São Paulo & 11 \\
\hline & & $\begin{array}{l}\text { Universidade Est. Paulista } \\
\text { Júlio de Mesquita Filho }\end{array}$ & 3 \\
\hline & & Pontifícia Universidade Católica de São Paulo & 5 \\
\hline & & Universidade Estadual de Campinas & 9 \\
\hline & & Universidade Federal de São Carlos & 3 \\
\hline & & Universidade Presbiteriana Mackenzie & 1 \\
\hline & \multirow{2}{*}{ RJ } & Fundação Oswaldo Cruz & 2 \\
\hline & & Universidade Federal do Rio de Janeiro & 1 \\
\hline & MG & Universidade Federal de Minas Gerais & 1 \\
\hline \multirow{4}{*}{$\begin{array}{l}\text { Nordeste } \\
(6 ; 12 \%)\end{array}$} & BA & Universidade Federal da Bahia & 1 \\
\hline & $\mathrm{CE}$ & Universidade Federal do Ceará & 2 \\
\hline & $\mathrm{PE}$ & Universidade Federal do Pernambuco & 1 \\
\hline & $\mathrm{RN}$ & $\begin{array}{l}\text { Universidade Federal do } \\
\text { Rio Grande do Norte }\end{array}$ & 2 \\
\hline Sul $(4 ; 8 \%)$ & RS & Universidade Federal do Rio Grande do Sul & 4 \\
\hline \multirow{3}{*}{$\begin{array}{l}\text { Centro-Oeste } \\
\qquad(3 ; 6 \%)\end{array}$} & \multirow[t]{2}{*}{ MS } & $\begin{array}{l}\text { Fundação Universidade Federal de Mato Grosso do } \\
\text { Sul }\end{array}$ & 1 \\
\hline & & Universidade Dom Bosco & 1 \\
\hline & GO & Universidade Federal de Goiás & 1 \\
\hline Norte $(1 ; 2 \%)$ & PA & Universidade Federal do Pará & 1 \\
\hline Total & & & 50 \\
\hline
\end{tabular}

Fonte: Elaborado pelos autores a partir dos dados coletados nos bancos de teses 
As frequências das produçóes encontradas por instituição coadunam em parte com dados evidenciado por Bueno (2014) sobre as produçôes em Educação Especial no geral. No entanto, no que se refere à instituição com maior número de publicaçôes aparece no estudo de Bueno (2014), a Universidade Federal de São Carlos, já neste estudo específico da deficiência visual essa instituição aparece na quinta posição, empatada com Universidade Estadual Paulista, com três produçóes. É intrigante a pouca produção desse programa nessa temática visto que essa instituição é tida como o "centro de referência em inclusão educacional no Brasil, pela qualidade e quantidade de produção científica” (SANTANA, 2011, p. 39). A instituição que contabilizou o maior número de teses foi a Universidade de Sáo Paulo, 11 ao todo, o que representa $22 \%$ das produçóes mapeadas.

Ao visualizarmos os dados por região, verificamos outra disparidade: concentração de $72 \%$ das produçóes na regiáo Sudeste; em segundo aparece a regiáo Nordeste, com 12\%; a região Sul com $8 \%$; a região Centro-Oeste com $6 \%$ e, por último, a regiáo Norte com $2 \%$. Esses números vêm confirmar os resultados de outros mapeamentos como de Bueno (2014), Cerva Filho (2014) que também constataram que a grande maioria pesquisas é realizada por instituiçôes localizadas na regiāo Sudeste. Acredita-se que esse fenômeno ocorra devido a concentraçôes de pesquisadores e de programas de Mestrado e Doutorado no Sudeste.

Com relação ao tipo de pesquisa e à opção metodológica, verificou-se a predominância da abordagem qualitativa. Dos 50 estudos mapeados, 5 foram desenvolvidos na abordagem quantitativa/qualitativa; 2 na abordagem quantitativa; 41 na abordagem qualitativa e em 2 delas não nos foi possível identificar esse aspecto somente a partir da análise do resumo. Esses dados mapeados são condizentes com que dizem Lüdke e André (2003, p. 11) "é cada vez mais evidente o interesse que os pesquisadores da área de educação vêm demonstrando pelo uso das metodologias qualitativas".

Dentre os estudos na abordagem qualitativa, encontramos 10 trabalhos que foram classificados como estudo de caso pelos próprios autores, sendo esse o tipo de pesquisa mais recorrente. Segundo Lüdke e André (2003, p. 19) o estudo de caso consiste em investigar um fenômeno de forma bem delimitada, com contornos definidos e "busca retratar a realidade de forma complexa e profunda".

No entanto, também, constatamos pesquisas classificadas pelos próprios autores como sendo: exploratória, descritiva, etnográfica, participativa, colaborativa, interpretativa, pesquisa-açáo, empírica e bibliográfica. Essas metodologias utilizadas são coerentes com a tendência contemporânea das pesquisas em educação (BOGDAN; BIKLEN, 1994; LÜDKE; ANDRÉ 2003; GIL, 2008).

Quanto aos instrumentos de coleta de dados, observamos que foram sempre utilizados mais que um em cada estudo. Algo também condescendente com as pesquisas nas Ciências Humanas (GIL, 2008). Entretanto, sobressaiu com maior frequência uso de questionários e entrevistas semiestruturadas. $\mathrm{O}$ uso de vários instrumentos de coleta de dados nos leva a inferir que houve nesses estudos a triangulaçáo dos dados. Para Gil (2008, p. 131) triangulação "refere-se ao uso de dois ou mais métodos 
para verificar se os resultados obtidos são semelhantes, com vistas a reforçar a validade interna dos resultados".

Apesar de a temática inventariada estar dentro de uma das subáreas da Educação, na Tabela de Área de Conhecimento da Capes, os 50 estudos mapeados foram realizados por 16 diferentes tipos de programas de doutoramento. Somente os programas de Doutorado em Educação e Educação Especial estão alocados na área de Educação, os quais contabilizaram juntos $46 \%$ das produçóes. Já $30 \%$ das teses foram realizadas por programas de doutoramento de áreas alheias que mantêm distância conceitual, filosófica e sociológica da educação. São eles os Programas strito sensu de Música, Oftalmologia, Arquitetura e Urbanismo, Engenharia Elétrica, Psicologia, Distúrbio de Desenvolvimento e de Ciências Biomédicas. Os outros 24\% das teses foram desenvolvidas em programas de outras áreas de conhecimento, mas, que possivelmente compreende uma interface com a área de educação, como os programas de Educação Matemática, Informática e Educação, Educação Física, Geografia, Ensino em Biociência e Saúde, Linguística e Química.

Cabe destacar que a concepção/compreensão do processo educacional de um pesquisador da área de Educação que está diretamente envolvido com o fenômeno é diferente de um pesquisador da área de Engenharia Elétrica, por exemplo. Sendo assim, ao mapearmos essas teses, mapeamos também uma diversidade de olhares de gente que atua em diferentes contextos do processo educacional de estudantes com deficiência visual. Isso porque, como abordam Lüdke e André (2003, p. 03), "a visão de mundo do pesquisador, os pontos de partida, os fundamentos para a compreensão e explicação desse mundo irão influenciar a maneira como ele propôe suas pesquisas". Isso de certa forma corrobora para que tenhamos um melhor retrato do fenômeno do processo educacional da pessoa com deficiência visual, ou seja, uma visão holística.

No que ser refere aos sujeitos envolvidos nas pesquisas, percebemos que estudantes foram ouvidos e investigados em pelos menos $74 \%$ dos estudos mapeados. Os professores foram a segunda categoria de sujeitos mais investigados. Esses números fazem sentido porque estudantes e professores são os principais personagens no meio educacional. Conforme pode ser evidenciado na Tabela 1, em pelos menos 36\% das pesquisas esses sujeitos, professores e estudantes foram ouvidos/investigados simultaneamente. Há também estudos como o de Faciola (2012) e Bazon (2006) que, além de estudantes e professores, envolveram também familiares dos estudantes.

Tabela 1 - Distribuiçáa dos sujeitos das pesquisas mapeadas

\begin{tabular}{|c|c|c|}
\hline Sujeitos dos Estudos & Quantidade & Porcentagem \\
\hline Professores & 3 & $6 \%$ \\
\hline Estudantes & 18 & $36 \%$ \\
\hline Professores e Estudantes & 13 & $26 \%$ \\
\hline $\begin{array}{c}\text { Estudantes Professores e } \\
\text { Familiares }\end{array}$ & 2 & $4 \%$ \\
\hline
\end{tabular}




\begin{tabular}{|c|c|c|}
\hline $\begin{array}{c}\text { Estudantes e Profissionais } \\
\text { da Escola }\end{array}$ & 4 & $8 \%$ \\
\hline Professores e Pais & 2 & $4 \%$ \\
\hline Náo Informou & 3 & $6 \%$ \\
\hline Outros Sujeitos & 5 & $10 \%$ \\
\hline Total & $\mathbf{5 0}$ & $\mathbf{1 0 0} \%$ \\
\hline
\end{tabular}

Fonte: Elaborado pelos autores a partir dos dados coletados nos bancos de teses

No entanto, grande parte dos estudos envolveu um número reduzido de sujeitos, algo condizente com a metodologia de pesquisa qualitativa (BOGDAN; BIKLEN, 1994). Nem todos os resumos analisados traziam o número de sujeitos da pesquisa. Dos que expressavam esse número, somente quatro trabalhos envolveram uma quantidade maior de sujeitos: uma pesquisa envolveu 115; outra, 102 e duas, 58 pessoas cada. Os demais estudos foram desenvolvidos com menos que dez sujeitos cada.

Para melhor explicitar/visualizar os conteúdos das pesquisas mapeadas, as organizamos no Quadro 3 por meio de focos e subfocos temáticos. Esses dados emergiram da confluência das subáreas da Educaçáo num geral e da análise prévia dos resumos. Contudo, os trabalhos que contemplavam mais de uma discussão foram enquadrados na que se sobressaiu na análise da conjuntura dos elementos explicitados nos resumos pelos autores.

Quadro 3 - Distribuição das 50 teses em focos e subfocos temáticos

\begin{tabular}{|c|c|c|}
\hline Foco & Subfoco & Autores \\
\hline \multirow{8}{*}{$\begin{array}{l}\text { Ensino-aprendizagem } \\
\qquad(14 ; 28 \%)\end{array}$} & Matemática & $\begin{array}{c}\text { Fernandes (2008); Vita (2012); Brandāo (2010); } \\
\text { Lopes (2012) }\end{array}$ \\
\hline & Física & Camargo (2004) \\
\hline & Inglês & Motta (2004) \\
\hline & Geografia & Sena (2009) \\
\hline & Não especificado & Silva (2004 b); Vilas Boas (2010); Munster (2004) \\
\hline & Educação Física & Junior (2008) \\
\hline & Música & Trintade (2008); Bonilha (2010) \\
\hline & Literatura & Régis (2010) \\
\hline \multirow{2}{*}{$\begin{array}{c}\text { Formação de } \\
\text { professores }(10 ; 20 \%)\end{array}$} & $\begin{array}{l}\text { Pensamento e } \\
\text { Prática Docente }\end{array}$ & $\begin{array}{c}\text { Baumel (1990); Gasparetto (2001); Gorgatti (2005); } \\
\text { Mazzaro (2007); Artioli (2008); Fernandes (2011); } \\
\text { Dorneles (2014) }\end{array}$ \\
\hline & $\begin{array}{l}\text { Formação para a } \\
\text { Prática Docente }\end{array}$ & Oliveira (2001); Chicon (2005); Field`s (2014) \\
\hline
\end{tabular}


Continuação do Quadro 3

\begin{tabular}{|c|c|c|}
\hline \multirow[t]{3}{*}{$\begin{array}{l}\text { Processo Educacional } \\
\qquad(21 ; 42 \%)\end{array}$} & Educação Básica & $\begin{array}{l}\text { Montilha (2001); Caiado (2002); Costa (2004); } \\
\text { Silva (2004a); Haddad (2006); Ormelezi (2006); } \\
\text { Santos (2007); Monteiro (2009); Bazon (2009); } \\
\text { Abate (2011); Bezerra (2011); Gomes (2012); Faciola } \\
\text { (2012); Marques (2013); Alves (2013) }\end{array}$ \\
\hline & Educação Especial & Vieira (2006); Pereira (2010) \\
\hline & Nível Superior & $\begin{array}{c}\text { Soares (2011); Guerreiro (2011); Passos (2012); } \\
\text { Morejon (2009) }\end{array}$ \\
\hline Tecnologia $(4 ; 8 \%)$ & Computador & $\begin{array}{c}\text { Sonza (2008); Carvalho (2001); Rodrigues (2007); } \\
\text { Monteiro (2010) }\end{array}$ \\
\hline Avaliaçāo $(1 ; 2 \%)$ & Avaliação & Bruno (2005) \\
\hline
\end{tabular}

Fonte: Elaborado pelos autores a partir dos dados coletados nos bancos de teses

A seguir, considerando cada um dos focos e subfocos apresentados no Quadro 3, descreveremos, de forma concisa e analítica, a produçáo brasileira de teses relativas ao processo educacional de pessoas com deficiência visual.

\section{Ensino-aprendizagem}

Dentre os 50 estudos, 14 (28\%) se voltaram a investigar o processo ensino e aprendizagem de estudantes com deficiência visual. A disciplina Matemática foi a mais recorrente nos estudos analisados, sendo que 4 estudos investigaram o seu ensino. No entanto, tivemos pesquisas que investigaram o processo ensino e aprendizagem de Física, Geografia, Inglês, Música, Educação Física, Literatura e três estudos que não se pautaram em uma única disciplina.

É interessante salientar que as disciplinas Matemática, Inglês, Geografia e Educaçáo Física foram apontadas por professores e estudantes com deficiência visual, num estudo realizado por Costa (2012), como os componentes curriculares mais problemáticos à inclusão.

Dentre os 14 estudos mapeados neste foco temático, 11 são estudos de natureza empírica experimental, em que os pesquisadores propuseram materiais adaptados, metodologias diferenciadas e avaliaram a aprendizagem de estudantes com deficiência visual frente ao uso desses.

Já o estudo de Silva (2004b) se pautou em investigar como o estudante cego aprende, o que deve ser ensinado e como ensiná-lo. Essa pesquisadora concluiu, ao término da investigação, que os estudantes cegos aprendem como os demais e que o melhor para o desenvolvimento deles é frequentar a sala de aula do ensino regular. Esse trabalho também aponta que a escola precisa prover assistência técnica com recursos e materiais adaptados para que esses estudantes tenham sucesso no processo de aprendizagem.

Vilas Boas (2010) investigou a compreensão textual de estudantes cegos alfabetizados em Braille e verificou que "em vários momentos, eles demonstraram di- 
ficuldade em integrar os seus conhecimentos prévios às informaçóes textuais para o estabelecimento das inferências".

Motta (2004), por sua vez, analisou a maneira como uma professora aprendeu a ensinar Inglês para estudantes cegos e com baixa visão.

Ao analisar os resultados a que chegaram cada um dos 14 estudos, percebemos que há um consenso entre os mesmos: os estudantes com deficiência visual não têm maiores dificuldades de aprender os conteúdos das diversas disciplinas analisadas se a eles forem oferecidos materiais adaptados que permitam o acesso aos registros e representaçôes dos conteúdos. Essa constatação já era defendida por Vygotski (1997) no início do século passado.

A criança cega e surda pode ter o mesmo desenvolvimento que a sem deficiência, mas para a criança com deficiência alcançar ela necessita de diferente modo, de um caminho diferente, com outros meios e para o professor é importante conhecer a particularidade do caminho que deve conduzir a criança” (VYGOTSKI, 1997 , p. 17) [tradução nossa] ${ }^{1}$.

Outros pesquisadores, como Amarilian (2009), Costa (2012) e Camargo (2008), também apontam essa questão sobre a educação de estudante com deficiência visual.

\section{Formação de professores}

Foram enquadrados neste foco $11(22 \%)$ pesquisas que analisaram, de forma direta ou indireta, a formaçáo de professores. As pesquisas de Baumel (1990); Gasparetto (2001); Gorgatti (2005); Mazzaro (2007) e Dorneles (2014) foram diagnósticas. Eles ouviram professores e profissionais de escolas apresentarem suas visôes sobre o processo de inclusão de estudantes com deficiência visual. Apesar das pesquisas terem sido desenvolvidas em localidades e anos diferentes, as conclusóes dos autores se convergiram à falta de preparação docente para a prática pedagógica com estudantes com deficiência visual e a escassez de material didático nas escolas para o ensino das diferentes disciplinas do currículo escolar.

As outras duas pesquisas do subfoco Pensamento e Prática Docente são: Artioli (2008) que investigou a afetividade de professores com os estudantes com deficiência visual; e Fernandes (2011) que analisou a criatividade de um professor de Artes na docência em sala de aula que tinha estudantes com deficiência visual.

No subfoco Formação para a Prática Docente encontramos os trabalhos de Oliveira (2001), Chicon (2005) e Field`s (2014) que promoveram e avaliaram açóes formativas para professores, no que se refere à prática pedagógica em contexto inclusivo que possuíam estudantes com deficiência visual. Nos três estudos é relatado o envolvimento direto dos pesquisadores com a pesquisa, já que essas se configuraram como pesquisa-ação/participantes. No entanto, os estudos de Oliveira (2001) e Chicon (2005) efetivaram intervenção formativa com professores em atividade, já o estudo de Field`s (2014), com professores em formação inicial. 
Contudo, os três estudos chegaram a conclusōes similares: intervençōes formativas com foco pontuais como o caso de inclusão de estudantes com deficiência visual acarreta aprendizagem docente significativa para a atuação num contexto escolar inclusivo.

\section{Processo educacional}

Neste foco temático foram enquadradas as produçôes que tiveram como objetivo maior o diagnóstico sobre o processo educacional de estudantes com deficiência visual e diferentes níveis e instituiçóes de ensino, 21 (42\%) tinham essa performance. Dentre as 21 teses, 15 tiveram como locus de investigação a Educação Básica e foram ouvidos e investigados professores, estudantes, profissionais de educação e alguns familiares, a fim de se buscar uma melhor compreensão desse fenômeno. Observa-se certo consenso nos resultados apurados, mesmo em estudos mais recentes, indicando que o processo de inclusão de estudantes com deficiência visual, por uma série de fatores, ainda não se tornou realidade na Educação Básica. Falta de material didático adaptado, salas de apoio que não estão atuando conforme a finalidade para que foi criada, professores que não conduzem suas aulas com metodologias que permitam a esses estudantes participarem ativamente do processo, livros de didático que não são impressos em Braille, além do descaso por parte de algumas escolas e professores com esses estudantes.

Já as pesquisas de Vieira (2006) e Pereira (2010) analisam instituiçóes de ensino especial. Vieira (2006) analisou o que estudantes com deficiência visual, egressos do Instituto Benjamim Constant, tinham a dizer sobre suas experiências de viver a deficiência visual e investigou também o papel a Educação Especial recebida no Instituto. Pereira (2010) analisou os impactos dos serviços prestados pelo Centro de Apoio Pedagógico do Maranhão na vida educacional de pessoas deficientes visuais.

Já os estudos de Soares (2010), Guerreiro (2011), Passos (2012) e Morejon (2009) tiveram como locus de investigaçáo instituiçóes de Ensino Superior. Esses estudos analisaram as políticas de acessibilidade de estudantes com deficiência visual no Nível Superior e os meandros do processo educacional vivenciado por acadêmicos com tal deficiência. Uma fala de Morejon (2009) sintetiza o resultado da sua pesquisa e dos outros três pesquisadores: "muito ainda precisa ser feito para que as instituiçóes educacionais oportunizem e incentivem uma educação para todos e o estudante com deficiência possa ter um projeto de vida concretizado na sociedade".

\section{Tecnologia}

Ficaram organizados neste foco 4 (8\%) estudos, os quais investigaram o uso de tecnologias no processo educacional de estudantes com deficiência visual. Sonza (2008), Carvalho (2001), Rodrigues (2007) e Monteiro (2010) discutiram a viabilidade do uso do computador no processo de educação de aprendiz com deficiência visual, sobre diferentes aspectos.

O estudo de Carvalho (2001) abordou possíveis adequações na Educação a Distância para que estudantes com deficiência visual possam ter acesso a todo o con- 
teúdo das aulas. Já Monteiro (2010) analisou a viabilidade da internet como programa de disseminação de informaçóes a respeito do uso de auxílios ópticos para baixa visão. Sonza (2008) investigou aspectos fundamentais em Ambientes Virtuais para que atendam à Acessibilidade, Usabilidade e Comunicabilidade para com deficientes visuais no contexto do Desenho Universal. Já o estudo de Rodrigues (2007) se pautou na construção de Centro de Apoio Pedagógico Virtual (CAP), estruturado em um portal Web para que possa servir como recurso auxiliar no apoio aos professores, no processo de inclusão de pessoas $\mathrm{cm}$ deficiência.

\section{Avaliação}

O único estudo dentre os 50 que discute a avaliação é o de Bruno (2005). Nesse trabalho o autor relata a elaboração de instrumentos de avaliação pedagógica para serem utilizados na Educação Infantil com crianças com deficiência.

Contudo, a análise dos aspectos gerais dos resumos das 50 teses nos mostram que, ainda que sejam pesquisas realizadas numa mesma temática que apresentam características comuns, expressam, também, uma diversidade de olhares, particularidades e abordagem. Isso as torna únicas, mas, vistas de forma conjunta, permitem esboçar um panorama nacional do processo educacional do estudante com deficiência visual.

\section{Considerações finais}

Cada uma das teses produzidas e aqui analisadas pode ser comparada a 50 peças de um mosaico. Cada peça possui diferente forma, configuraçáo própria, originalidade, singularidade, identidade e materialidade. Entretanto, quando reunidas possibilitam formar desenhos diversos, com as quais uma peça se complementa na outra, sem perder sua essência. Ao analisarmos individualmente e numa conjuntura as 50 teses mapeadas, conseguimos interpretar o seguinte esboço: $\mathrm{O}$ processo educacional da pessoa com deficiência visual ainda representa um grande desafio para o sistema de ensino brasileiro.

Isso acontece porque a esmagadora maioria, se não a totalidade, de estudantes com essa deficiência está matriculada em escolas de ensino regular. No entanto, não estáo inclusos nessas escolas por uma série de motivos.

Os principais motivos dessa exclusão são a falta de preparo dos professores para fazerem com que estudantes com deficiência visual participem das aulas, falta material impresso em Braille, escassez de material didático adaptado (materiais necessários no processo de ensino de várias disciplinas), estruturas física de escolas que não atendem as necessidades desses estudantes, profissionais do atendimento educacional complementar que não dominam o código de escrita em Braille e o manuseio do Sorobã para ensinar e estes estudantes e a, ainda, existência de preconceito de professores e profissionais da educaçáo em relação à potencialidade desses estudantes.

Contudo, algumas peças desse desenho nos apontam pistas para podermos vencer o desafio de incluir estudantes com deficiência visual nas escolas de ensino 
regular: unir esforços e promover mudanças nos cursos de formação inicial de professores incorporando disciplinas que possibilitem discutir a temática, aproximar os professores em formação inicial da realidade do ensino inclusivo e oferecer cursos com estudos teóricos e instrumentalização para os professores que estáo em sala de aula. A possibilidade de uso de tecnologias que têm mostrado caminhos plausíveis, tanto para serem utilizadas como tecnologia assistida para o estudante com deficiência visual, quanto para a promoção de formação de professores, como também para a divulgação de orientação referente à inclusão de estudantes deficiente visuais.

O que está bem nítido no grupo de peças do desenho em análise é que o estudante com deficiência visual não tem maiores dificuldades de aprendizado. Ele só necessita de condição de acesso na íntegra aos conteúdos. Para tanto, faz-se necessária à adaptação de materiais pedagógicos e diversificação da prática pedagógica.

Com isso, espera-se que os resultados deste mapeamento de teses possam propiciar e subsidiar reflexóes, discussóes e realização de novos estudos, quiçá, mudanças acerca da realidade do processo de in/exclusão que os estudantes com deficiência visual estão vivenciando nas escolas brasileiras.

\section{Referências}

ABATE, T. P. Instrumentos de Avaliaçáo Pós-Ocupação (APO) adaptados a pré-escolares com deficiência física, auditiva e visual. 2011. 491f. Tese (Doutorado) - Universidade de São Paulo, Faculdade de Arquitetura e urbanismo, Programa de Pós-Graduação em Tecnologia da Arquitetura, São Paulo. Disponível em: <http:// www.teses.usp.br/teses/disponiveis/16/16132/tde-27012012-094114/pt-br.php>. Acesso em: 12 nov. 2014.

ALVES, M. L. T. O aluno com deficiência visual nas aulas de educaçáo física: análise do processo inclusivo. 2013. Tese (Doutorado) - Universidade Estadual de Campinas, Programa de Pós-Graduação em Educação Física, Campinas. Disponível em: <www.bibliotecadigital.unicamp.br > Bases Disponíveis>. Acesso em: 12 nov. 2014.

AMIRALIAN, M. L. T. M. Comunicação e Participação Ativa: a inclusão de pessoas com deficiência visual. In: AMIRALIAN, M. L. T. M. (Org.). Deficiência Visual: perspectivas na contemporaneidade. 1. ed. São Paulo: Vetor, 2009. p. 19-38.

ARTIOLI, A. L.; Reaçáo emocional do professor na relaçáo com o aluno com deficiência. 2008. Tese (Doutorado) - Pontifícia Universidade Católica de Sáo Paulo, Programa de Pós-Graduaçáo Psicologia, Sáo Paulo. Disponível em: <http://www.dominiopublico.gov.br/pesquisa/DetalheObraForm.do?select_action=\&co_obra $=106315>$. Acesso em: 10 mai. 2014.

BAZON, F. V. M.; As mútuas influências, família-escola, na inclusão escolar de crianças com deficiência visual. 2009. 574f. Tese (Doutorado) - Universidade de São Paulo, Programa de Pós-Graduaçáo em Educação, São Paulo. Disponível em: <http://www.google.com.br/url?sa=t\&rct=j\&q=\&esrc=s\&frm=1\&source=web \&cd $=1 \&$ ved=0CB0QFjAA \&url $=$ http $\% 3 \mathrm{~A} \% 2 \mathrm{~F} \% 2 \mathrm{Fwww}$.teses.usp.br\%2Fteses\%2Fdisponiveis\%2F48\%2F48134\%2Ftde-14122009-102937\%2Fpublico\%2FFernanda_Vilhena_Madra_Bazon.pdf\&ei $=$ oyxmVc60O8jIsQTI4IHIBg\&usg= AFQjCNH39Bpt3p9PhLNTDhgm_f6jWHxn6A $>$. Acesso em: 12 nov. 2014.

BAUMEL. R. C. R. C. Habilidades do Professores dos Portadores de Deficiência Visual - Estado do Paraná. 1990. Tese (Doutorado) - Universidade de São Paulo, Programa de Pós-Graduação em Educação, São Paulo.

BEZERRA, M. L. E.; Inclusão de Pessoas com Deficiência Visual na Escola Regular: Bases Organizativas e Pedagógicas no Estado do Acre. 2011. 257f. Tese (Doutorado) - Universidade Federal de Minas Gerais, Faculdade de Educação, Programa de Pós-Graduação em Educação, Belo Horizonte. Disponível em: <http://www. bibliotecadigital.ufmg.br/dspace/handle/1843/505>. Acesso em: 12 nov. 2014.

BOGDAN, R. C.; BIKLEN, S. K.; Investigaçáo Qualitativa em educaçáo: uma introdução á teoria e aos métodos. Tradutores: Maria Joáo Alvarez, Sara Bahia dos Santos e Telmo Mourinho Baptista. Porto - Portugal: Porto Editora, 1994. 
BONILHA, F. F. G.; Do toque ao som: o ensino da musicografia braille como um caminho para a educaçáo musical inclusiva. 2010. Tese (Doutorado) - Universidade Estadual de Campinas, Programa de PósGraduação em Música, Campinas. Disponível em: <http://www.bibliotecadigital.unicamp.br/document/?code $=000777480>$. Acesso em: 12 nov. 2014

BRADÃO, J. C. Matemática e Deficiência Visual. 2010. 152f. Tese (Doutorado) - Universidade Federal do Ceará, Faculdade de Educação, Programa de Pós-graduação em Educação. Disponível em: <http://www.repositorio.ufc.br/handle/riufc/3110>. Acesso em: 20 fev. 2015.

BRASIL. Ministério da Educação. Lei no 9.394, de 20 dezembro de 1996. Estabelece as diretrizes e bases da educação nacional. Diário Oficial da Uniáo, Brasília, 23 dez. 1996. Disponível em: <http://www.planalto.gov. br/ ccivil_03/leis/L9394.htm>. Acesso em: 12 abr. 2014.

Decreto no 5.296, de 2 de dezembro 2004. Regulamenta as Leis n. 10.048, de 8 de novembro de 2000, que dita prioridade de atendimento das pessoas que especifica, e 10.098, de 19 de dezembro de 2000, que estabelece normas gerais e critérios básicos para a promoção da acessibilidade das pessoas portadoras de deficiência ou com mobilidade reduzida, e dá outras providências. 2004. Disponível em: <http://www.planalto.gov.br/ ccivil_03/_ato2004-2006/2004/decreto/d5296.htm >. Acesso em: 10 abr. 2014.

BRUNO, M. D. M. G. Avaliação educacional para alunos com baixa visão e múltipla deficiência na educaçáo infantil: uma proposta para adaptação e elaboração de instrumentos. 2005. Tese (Doutorado) - Universidade Est. Paulista Júlio De Mesquita Filho/Marilia Disponível em: <http://biblioteca.ufgd.edu.br/ faces/consulta_resultado.xhtml?termo=\%22Bruno $\% 20$ Marilda $\% 20$ Moraes $\% 20$ Garcia $\% 22 \&$ filtro=autores $\&$ faces-redirect=true>. Acesso em: 12 nov. 2014 .

BUENO, J. G. S.; A pesquisa brasileira sobre Educação Especial: balanço tendencial das dissertaçóes e teses brasileiras (1987-2009). In: BUENO, J. G. S.; MUNAKATA, K.; CHIOZZINIA, Daniel Ferraz (Org.). A escola como objeto de estudo: escola, desigualdades, diversidades. 1 ed. Araraquara: Junqueira \& Marin, 2014. p. $211-244$.

K. R. M. Lembranças da escola: historias de vida de pessoas deficientes visuais. 2002. 211f. Tese (Doutorado em Educação) - Universidade de São Paulo, São Paulo, 2002.

CAMARGO, E. P. Ensino de Física e Deficiência Visual: dez anos de investigaçôes no Brasil. São Paulo: Plêiade, 2008. 205p.

E. P. O ensino de física no contexto da deficiência visual: elaboração e condução de atividades de ensino de física para alunos cegos ou com baixa visão. 2004. 285f. Tese (Doutorado) - Universidade Estadual de Campinas. Faculdade de Educação, Programa de Pós-Graduação em Educação, Campinas. Disponível em:< http://www.bibliotecadigital.unicamp.br/document/? code=vtls000358628>. Acesso em: 12 nov. 2014.

CAVARLHO, J. O. F. Soluçóes tecnológicas para viabilizar o acesso do deficiente visual a educaçáo a distancia no ensino superior. 2001. Tese (Doutorado) - Universidade Estadual de Campinas. Faculdade de Engenharia Elétrica e de Computação, Campinas. Disponível em: <http://www.bibliotecadigital.unicamp.br/ document/? code=vtls000358628>. Acesso em: 12 nov. 2014.

CERVA FILHO, O. A. Educação Matemática e o aluno cego: ação docente frente à inclusáo. 2014. 135f. Dissertação (Mestrado) - Universidade Luterana do Brasil, Programa de Pós-Graduação em Ensino de Ciências e Matemática, Canoas. Disponível em: <http://www.ppgecim.ulbra.br/teses/index.php/ppgecim/article/ view/185>. Acesso em: 11 mai. 2015.

CHICON, J. F. Inclusão na educação física escolar: construindo caminhos. 2005. Tese (Doutorado) - Universidade de São Paulo, Programa de Pós-Graduação em Educação, São Paulo. Disponível em: <www.observatoriodaeducacao.org.br/ebulicao/ebul20/cal_verde_03.html>. Acesso em: 12 nov. 2014.

COSTA, V. B. Inclusão Escolar do com deficiência visual no ensino regular. Jundiaí: Paco Editorial, 2012. 192 p.

COSTA, L. G. Apropriaçáo tecnológica e ensino: as tecnologias de informação e comunicação e o ensino de física para pessoas com deficiência visual. 2004. Tese (Doutorado) - Universidade Federal do Rio Grande do Sul, Programa de Pós-Graduação em Informática na Educação. Disponível em: <http://www.lume.ufrgs. $\mathrm{br} /$ handle/10183/1/filtersearch?ANY=\&tdautor=Luciano+Gon\%C3\%A7alves+Costa\&tdorientador $=\& \mathrm{ti}-$ tle $=\&$ keyword $=\&$ date year $=2004 \&$ mimetype $=\% 5 \mathrm{BA}+\mathrm{TO}+\mathrm{Z} \% 5 \mathrm{D} \&$ language $=\& \mathrm{rpp}=10 \&$ sort_by $=0 \&$ order $=-$ DESC\&submit=Enviar>. Acesso em: 12 nov. 2014.

DORnEleS, C. M. A Concepção Dos Professores Sobre In/Exclusão de Estudantes Com Deficiência Visual Na Educaçáo Básica. 2014. 228f. Tese (Doutorado) - Universidade Católica Dom Bosco, Programa de Pós-Graduação em Educação, Campo Grande. Disponível em:< http://site.ucdb.br/public/md-dissertacoes/13931-dorneles-claunice-maria-doutora-ucdb-2014.pdf >. Acesso em: 12 ab. 2015. 
DUEK, V. P. Educaçáo Inclusiva e Formaçáo Continuada: Contribuiçôes dos casos de ensino para o processo de aprendizagem e desenvolvimento profissional de professores. 2011.333p. Tese (Doutorado) - Universidade Federal do Rio Grande do Norte, Programa de Pós-Graduaçấo em Educação. Disponível em: <http://repositorio.ufrn.br:8080/jspui/bitstream/1/10374/ 1/VivianePD_TESE.pdf>. Acesso em: 12 nov. 2014.

FACIOLA, R. A. A Escola Inclusiva enquanto Contexto de Desenvolvimento: Um Estudo dos Fatores de Risco e Proteção. 2012. 192f. Tese (Doutorado) - Universidade Federal do Pará, Núcleo de Teoria e Pesquisa do Desenvolvimento, Programa de Pós-Graduação em Teoria da Pesquisa do Desenvolvimento. Disponível em: <http://www.ufpa.br/ppgtpc/dmdocuments/DOUTORADO/Tese\%20de\%20Doutorado\%20Rosana\%20 Assef\%20Faciola.pdf>. Acesso em: 12 nov. 2014.

FERNANDES, V. L. P. A criatividade no trabalho pedagógico do professor de Artes Visuais no Ensino Médio, no contexto da Educaçáo Inclusiva. 2011. Tese (Doutorado) - Universidade Federal do Mato Grosso do Sul, Programa de Pós-Graduação em Educação. Disponível em: <http://www.cbc.ufms.br/Biblioteca>. Acesso em: 12 nov. 2014

FERNANDES, S. H. A. A. Das experiências sensoriais aos conhecimentos matemáticos: uma análise das práticas associadas ao ensino e aprendizagem de alunos cegos e com visão subnormal numa escola inclusiva. 2008. Tese (Doutorado) - Pontifícia Universidade Católica de São Paulo, Programa de Pós-Graduação em Informática, São Paulo. Disponível em: <http://www.dominiopublico.gov.br/pesquisa/DetalheObraForm.do?select_ action $=\&$ co_obra $=124330>$. Acesso em: 10 mai. 2014 .

FIELD'S, K. A. P. Saberes profissionais para o exercício da docência em Química voltado à educaçáo inclusiva. 2014.195f. Tese (Doutorado) - Universidade Federal de Goiás. Instituto de Química, Programa de Pós-Graduação em Química, Goiânia. Disponível em: <https://repositorio.bc.ufg.br/tede/handle/tde/3044>. Acesso em: 10 fev. 2015.

GASPARETTO, M. E. R. F. Visáo subnormal em escolas públicas: conhecimentos, opiniáo e conduta de professores e diretores do ensino fundamental. 2001, 250p. Tese (Doutorado) - Universidade Estadual de Campinas. Faculdade de Ciências Médicas, Programa de Pós-Graduação em Ciências Médicas, Campinas. Disponível em: <http://www.bibliotecadigital.unicamp.br/document/?code $=\mathrm{vtl}$ s $000225752 \& \mathrm{fd}=\mathrm{y}>$. Acesso em: 10 fev. 2015.

GORGETTI, M. G. Análise do desenvolvimento motor e social de adolescentes com deficiência visual e das atitudes dos professores de educaçáo física: um estudo sobre a inclusão. 2005. 157f. Tese (Doutorado) - Universidade de São Paulo, Programa de Pós-Graduação em Educação Física, São Paulo. Disponível em: <http://www.teses.usp.br/teses/disponiveis/39/39132/tde-18042007-135446/pt-br.php>. Acesso em: 12 nov. 2014.

GIL, A. C. Como Elaborar Projetos de Pesquisa. São Paulo: Editora Atlas, 2008.

GOMES, A. E. G. Inclusão de alunos com deficiência nas aulas de educação física escolar em escolas públicas municipais de Fortaleza (CE). 2012. 158f. Tese (Doutorado) - Universidade Presbiteriana Mackenzie, Programa de Pesquisa e Pós-Graduação em Distúrbio do Desenvolvimento, São Paulo. Disponível em: <http:// tede.mackenzie.com.br/tde_arquivos/5/TDE-2013-03-01T144406Z-1534/Publico/Ana\%20Elizabeth\%20 Gondim\%20Gomes.pdf>. Acesso em 10 abr. 2014.

GUERREIRO, E. M. B. R. Avaliaçáo da satisfaçáo do aluno com deficiência no ensino superior: estudo de caso da UFSCar. 2011. Tese (Doutorado) - Universidade Federal de São Carlos, Programa de Pesquisa e Pós-Graduação em Educação Especial, São Carlos. Disponível em: <http://www.ppgees.ufscar.br/dissertacoesdefendidas/teses-defendidas>. Acesso em 10 abr. 2014.

HADDAD, M. A. O. Habilitaçáo e reabilitaçáo visual de escolares com baixa visáo: aspectos médico-sociais. 2006. Tese (Doutorado) - Universidade de São Paulo, Faculdade de Medicina, Programa de Pós-Graduação em Oftalmologia, São Paulo. Disponível em: <http://www.teses.usp.br/teses/disponiveis/5/5149/tde-23112006133322/pt-br.php> Acesso em: 10 nov. 2014

JUNIOR, M. 1. O. S. Estratégias de ensino e recursos pedagógicos para o ensino do aluno com deficiência visual na atividade física adaptada. 2008. 128f. Tese (Doutorado) - Universidade Estadual Paulista Júlio de Mesquita Filho, Programa de Pós-Graduaçáo em Educação, Marília. Disponível em: <http://www.marilia. unesp.br/Home/Pos-Graduacao/Educacao/Dissertacoes/junior_mos_dr_mar.pdf>Acesso em: 05 mar. 2014.

LOPES, A. M. A. Estratégias de Mediaçáo para o Ensino de Matemática com Objetos de Aprendizagem acessíveis: Um estudo de caso com alunos com deficiência visual. 2012. Tese (Doutorado) - Universidade Federal do Rio Grande do Sul, Programa de Pós-Graduação em Informática na Educação, Porto Alegre. Disponível em: <http://www.pgie.ufrgs.br/index.php? cad=pes\&incad=teses\&profdet=32>. Acesso em: 11 mai. 2014 
LUDKE, M. ANDRÉ, M. E. D. A. Pesquisa em Educaçáo: abordagens qualitativas. 6a ed. São Paulo: Editora Pedagógica e Universitária (EPU), 2003.

MARQUES, L. C. Consultoria Colaborativa Escolar na área de deficiência visual ocular e cortical. 2013. Tese (Doutorado) - Universidade Federal de São Carlos, Programa de Pesquisa e Pós-Graduação em Educação Especial, São Carlos. Disponível em: <http://www.bdtd.ufscar. br/htdocs/tedeSimplificado//tde_busca/arquivo. php?codArquivo=6237>. Acesso em 03 abr. 2015.

MAZZARO, J. L. Baixa Visão na Escola: Conhecimento e opinião de Professores e de Pais de alunos deficientes visuais, em Brasília, DF. 2007. Tese (Doutorado) - Universidade Estadual de Campinas, Faculdade de Ciências Médicas, Programa de Pós-Graduação em Ciências Médicas, Campinas. Disponível em: <http://www. bibliotecadigital.unicamp.br/document/?code=vtls000428305>. Acesso em: 10 mai. 2014.

MAZZOTTA, M. J. S. Educação Especial no Brasil: história e políticas públicas. 6. ed. São Paulo: Cortez, 2011.

MENEZES, M. A. Formaçáo de Professores de estudantes com necessidades educacionais especiais no ensino regular. 2008, 250p. Tese (Doutorado) - Pontifícia Universidade Católica de São Paulo, Programa de Pós-Graduação em Educação (Currículo), São Paulo. Disponível em: <http://www.educadores.diaadia.pr.gov. br/arquivos/File/2010/artigos_teses/2010/Pedagogia/tform_prof_estudantes_neces_esp.pdf $>$. Acesso em: 10 mai. 2014.

MONTEIRO, L. M. F. S. O corpo como agente da cogniçáo de crianças cegas: uma questáo de experiência. 2009. Tese (Doutorado) - Universidade Federal do Rio de Janeiro. Faculdade de Pisicologia, Programa de Pós-Graduação em Psicologia, Rio de Janeiro. Disponível em: <http://www.dominiopublico.gov.br/pesquisa/ DetalheObraForm.do?select_action=\&co_obra=150259>. Acesso em: 15 mai. 2014 .

MONTEIRO, G. B. M. Auxílios opticos para baixa visáo: uso de internet na orientação de professores de deficientes visuais. 2010. Tese (Doutorado) - Universidade Estadual de Campinas. Faculdade de Ciências Médicas, Programa de Pós-Graduação em Ciências Biomédicas, Campinas. Disponível em: <www.bibliotecadigital. unicamp.br/document/?view=000478984>. Acesso em: 14 mai. 2014.

MONTILHA, R. C. I. Escolarizaçáo e reabilitaçáo de portadores de deficiência visual: percepçáo de escolares e açóes de reabilitaçáo. 2001. 157f. Tese (Doutorado) - Universidade Estadual de Campinas. Faculdade de Ciências Médicas, Programa de Pós-Graduação em Ciências Médicas, Campinas. Disponível em: <http:// www.bibliotecadigital.unicamp.br/document/?code=vtls00022575 2\&fd= y>. Acesso em: 10 mai. 2014.

MOREJON, K. O acesso e a acessibilidade de pessoas com deficiência no ensino superior público no Estado do Rio Grande do Sul. 2009. Tese (Doutorado) - Universidade de São Paulo, Programa de Pós-Graduação em Psicologia, São Paulo. Disponível em: <http://www.ffclrp.usp.br/imagens_defesas/30_05_2011_09_01_45_61.pdf>. Acesso em: 11 mar. 2014.

MOTTA, L. M. V. M. Aprendendo a ensinar inglês para alunos cegos e de baixa visão - um estudo na perspectiva da teoria da atividade. 2004. 201f. . Tese (Doutorado) - Pontifícia Universidade Católica de São Paulo, Programa de Pós-Graduação em Lingüística Aplicada e Estudos da Linguagem, São Paulo. Disponível em: <http://www.vercompalavras.com.br/pdf/tesedoutorado.pdf>. Acesso em: 10 mai. 2014.

MUNSTER, M. A. V. Esportes na Natureza e Deficiência Visual: Uma Abordagem Pedagógica. 2004. $332 f$. Tese (Doutorado) - Universidade Estadual de Campinas, Faculdade de Educação Física, Programa de Pós-Graduação em Educação Física, Campinas. Disponível em: <http://www.bibliotecadigital.unicamp.br/document/?code $=$ vtls $000353138>$. Acesso em: 05 mar. 2014.

OLIVEIRA, F. I. W. O professor diante da inclusáo do aluno com visáo subnormal: a utilizaçáo de materiais didáticos adaptados para o ensino. 2001. Tese (Doutorado) - Universidade Estadual Paulista Júlio de Mesquita Filho, Programa de Pós-Graduação em Educação, Marília. Disponível em: < http://geodados.pg.utfpr.edu.br/ busca/detalhe.php?id=37124. Acesso em Acesso em: 05 mar. 2014.

ORGANIZAÇÃO DAS NAḈES UNIDAS PARA A EDUCAÇÃO, A CIÊNCIA E A CULTURA. Declaraçáo de Salamanca sobre princípios, política e prática em Educaçáo Especial. Genebra, 1994. Disponível em: <http://www.direitoshumanos.usp.br/index.php/UNESCO-Organiza\%C3\%A7\%C3\%A3o-das-Na\%C3\%A7\%C3\%B5es-Unidas-para-a-Educa\%C3\%A7\%C3\%A3o-Ci\%C3\%AAncia-e-Cultura/declaracao-desalamanca-sobre-principios-politica-e-pratica-em-educacao-especial.html>. Acesso em: 20 abr. 2013.

ORMELEZI, E. M. Inclusáo educacional e escolar: uma leitura psicanalítica do estudo de caso de uma criança cega congênita com problemas na constituição subjetiva e no desenvolvimento global. 2006. Tese (Doutorado) - Universidade de Sáo Paulo, Faculdade de Educação, Programa de Pós-Graduação em Educação, Sáo Paulo. Disponível em: <http://www.teses.usp.br/teses/disponiveis/48/48131/tde-13072007-155541/pt-br. php>. Acesso em: 05 mar. 2014. 
PANSINI, F.; MATOS, M. A. S. “Tapando o sol com a peneira”: inclusão escolar no Estado de Rondônia. In: VI Congresso brasileiro de Educação Especial e IX Encontro Nacional dos Pesquisadores da Educação Especial, 11, 2014, Sáo Carlos . Anais... São Carlos: Disponível em: <http://2014.cbee-ufscar.com.br/>. Acesso em: 02 jan. 2015.

PASSOS, M. W. C. A facilitaçáo do acesso de alunos com deficiência visual ao ensino superior na área biomédica: pesquisa para o desenvolvimento e avaliação de materiais e métodos aplicáveis ao estudo de disciplinas morfológicas. 2012. 126f. Tese (Doutorado) - Fundação Oswaldo Cruz, Instituto Oswaldo Cruz, Programa de Pós-Graduação em Ensino em Biociências e Saúde, Rio de Janeiro. Disponível em: <http://www.arca.fiocruz.br/ handle/icict/6411>. Acesso em: 11 mai. 2014.

PEREIRA, J. L. C. Centro de Apoio Pedagógico: avaliação dos serviços CAP - Maranhão para a educação de pessoas com deficiência visual. 2010. Tese (Doutorado) - Universidade Federal de Sáo Carlos, Programa de Pesquisa e Pós-Graduação em Educação Especial, São Carlos. Disponível em: <http://www.ppgees.ufscar.br/ dissertacoes-defendidas/teses-defendidas>. Acesso em 13 abr. 2014

RÉGIS, M. C. A. S. Categorias Literárias, programas de áudio para o incentivo à leitura de deficientes visuais: um olhar transdisciplinar. 2009. Tese (Doutorado) - Universidade de São Paulo, Faculdade de Educação, Programa de Pós-Graduação em Educação, São Paulo. Disponível em: <http://www.teses.usp.br/teses/ disponiveis/48/48134/tde-11092009-162239/en.php>. Acesso em: 11 mar. 2014.

RODRIGUES, A; S. A Informática como uma Ferramenta de Apoio a Inclusáo do Deficiente Visual: Centro de Apoio Pedagógico Virtual para o Apoio a Inclusão do Deficiente Visual no Ensino Superior. 2007. Tese (Doutorado) - Universidade Federal do Rio Grande de Norte, Programa de Pós-Graduação em Educação. Disponível em: <http://posugf.com.br/biblioteca/index.php>. Acesso em: 11 maio 2014.

SANTANA, C. S. O. C. Educaçáo inclusiva no Brasil: Revisão sistemática e análise bioecológica. $2011.81 f$. Dissertação (Mestrado) - Universidade Federal do Pará, Programa de Pós-Graduação em Teoria e Pesquisa Comportamental. Disponível em: <http://www.ufpa.br/ppgtpc/dmdocuments/mestrado/dissertacaoclaudiaoliveira.pdf>. Acesso em: 10 abr. 2014.

SANTOS, S. S. Linguagem e Subjetividade do Cego na Escolaridade Inclusiva. 2007. 202f. Tese (Doutorado) - Universidade Federal do Rio Grande do Sul, Programa de Pós-Graduação em Educação, Porto Alegre. Disponível em: <http://www.centroruibianchi.sp.gov.br/usr/share/files/artigos/SueliSouzadosSantos.pdf>. Acesso em: 11 maio 2014.

SENA, C. C. R. G. Cartografia tátil no ensino de geografia: uma proposta metodológica de desenvolvimento e associação de recursos didáticos adaptados a pessoas com deficiência visual. 2009. Tese (Doutorado) - Universidade de São Paulo, Programa de Pós-Graduação em Geografia, São Paulo. Disponível em: <www.teses.usp.br/ teses/disponiveis/8/8136/tde-02072014.../pt-br.php>. Acesso em: 11 mar. 2014.

SILVA, L. M. A Negaçáo da Diferença: Um Estudo Sobre as Interaçóes de Alunos com Deficiência Visual na Escola Pública. 2004a. 352f. Tese (Doutorado) - Pontifícia Universidade Católica de São Paulo, Programa de Pós-Graduaçáo em Educação: História, Política e Sociedade, São Paulo. Disponível em: <www.cdi.uneb.br/ pdfs/teses/2004/luciene_maria_da_silva.pdf $>$. Acesso em: 11 maio 2014.

SILVA, L. G. D. S. Inclusão: uma questão também de visão? Estratégias de ensino utilizadas com uma criança cega. 2004b. Tese (Doutorado) - Universidade Federal do Rio Grande de Norte, Programa de Pós-Graduação em Educaçáo, Natal. Disponível em: <http://posugf.com.br/biblioteca/index.php>. Acesso em: 11 maio 2013.

SOARES, A. C. S. A inclusão de alunos com deficiência visual na Universidade Federal do Ceará: estudo sobre ingresso e permanência na ótica dos alunos, docentes e administradores. 2011. Tese (Doutorado) - Universidade Federal do Ceará, Faculdade de Educação, Programa de Pós-graduação em Educação, Fortaleza. Disponível em: <http://www.repositorio.ufc.br/bitstream/riufc/2771/1/2011_tese_acssoares.pdf>. Acesso em: 20 fev. 2015.

SONZA, A. P. Ambientes virtuais acessíveis sob a perspectiva de usuários com limitaçáo visual. 2008. Tese (Doutorado) - Universidade Federal do Rio Grande do Sul, Programa de Pós-Graduaçấo em Informática na Educação, Porto Alegre. Disponível em:< http://www.ufrgs.br/niee /pesquisas.php? pg=2>. Acesso em: 11 mar. 2014.

STAINBACK, S. STAINBACK, W. Inclusáo: um guia para educadores. Traduzido por Magda França Lopes. Porto Alegre: Artmed, 1999.

TEIXEIRA, P. M. M. NETO MEGID, J. Investigando a Pesquisa Educacional: Um estudo Enfocando Dissertaçōes e Teses sobre o Ensino de Biologia no Brasil. 2002. Disponível em: <http://www.if.ufrgs.br/public/ ensino/vol11/n2/v11_n2_a6.htm>. Acesso em: 20 abr. 2014. 
TRINDADE, B. G. Abordagem musical Clatec: uma proposta de ensino de música incluindo educandos com deficiência visual. 2008. Tese (Doutorado) - Universidade Federal da Bahia, Programa de Pós-Graduação em Educação, Slavador. Disponível em: <https://repositorio.ufba.br/.../Tese\%20Versão\%20final\%20ABNT\%20 21>. Acesso em: 11 mai. 2014.

URZÊDA, M. O. M. As políticas de Formação de professores para inclusão na perspectiva da diversidade social. 2012.118 f. Dissertação (Mestrado) - Universidade Católica de Gois, Programa de Pesquisa e Pós-Graduação em Educação. Disponível em: <http://tede.biblioteca.ucg.br/tde_busca/arquivo.php?codArquivo=1261>. Acesso em: 13 abr. 2014 .

VIEIRA, C. S. Alunos cegos egressos no Instituto Benjamin Constant (IBC) no período 1985 a 1990 e sua inserçáo comunitária. 2006. Tese (Doutorado) - Fundação Oswaldo Cruz, Instituto Oswaldo Cruz, Programa de Pós-Graduaçáo em Saúde Pública, Rio de Janeiro. Disponível em: <http://thesis.icict.fiocruz.br/php/index. php>. Acesso em: 11 mai. 2014.

VILAS BOAS, L. L. Compreensáo textual de alunos cegos com o domínio do Braille. 2010. Tese (Doutorado) - Universidade Federal do Pernambuco, Programa de Pós-Graduação em Psicologia, Recife. Disponível em: <hhttp://www.dominiopublico.gov.br/pesquisa/DetalheObraForm.do?select_action=\&co_obra=187779> . Acesso em: 20 mai. 2014.

VITA, A. C. Análise instrumental de uma Maquete Tátil para a Aprendizagem de Probabilidade por alunos cegos. 2012. Tese (Doutorado) - Pontifícia Universidade Católica de São Paulo, Programa de Pós-Graduação em Ensino de Ciências e Matemática, Sáo Paulo. Disponível em: <http://www.sapientia.pucsp.br/tde_busca/ processaPesquisa.php?listaDetalhes\%5B\%5D=12247\&processar=Processar>. Acesso em: 10 mai. 2013.

VYGOTSKI, L. S. Fundamentos da defctologia. In: Obras Escogidas: Tomo V. Espanha: Visor, 1997.

\section{Notas}

${ }^{1}$ El nińo ciego o sordo puede lograr en el desarrollo lo mismo que el normal, pero los nińos con defecto lo logran distinto modo, por un camino distinto con otros medios, y para el pedagogo es importante conocer la peculiaridad del camino por el cual debe conducir al niño.

\section{Agradecimentos}

À Coordenação de Aperfeiçoamento de Pessoal de Nível Superior (CAPES) pelas bolsas de estudos concedidas.

\section{Correspondência}

Marcia Rosa Uliana - Universidade Federal de Rondônia, Departamento de Matemática e Estatística. Rua Rio Amazonas - de 452/453 a 722/723, Jardim dos Migrantes. CEP: 76900633 - Ji-Paraná, Rondônia, Brasil.

E-mail: marcia.rosa@unir.br-gmol@unb.br

Recebido em 30 de outubro de 2015

Aprovado em 19 de janeiro de 2017 